\title{
LA COMPleMENTARIEDAD DE LA CORTE PENAL INTERNACIONAL SEGÚN EL TRIBUNAL CONSTITUCIONAL CHILENO*
}

\section{SEBASTIÁN LÓPEZ ESCARCENA**}

RESUMEN: Una sentencia del Tribunal Constitucional de 2002 declaró que la aprobación y posterior ratificación del Estatuto de Roma requería una reforma constitucional previa. Entre los motivos seńalados, la sentencia destacó el supuesto carácter correctivo y sustitutivo de la jurisdicción de la Corte Penal Internacional, respecto de la competencia de los tribunales nacionales. La introducción de una nueva disposición transitoria en nuestra carta fundamental facultó el 2009 al Estado chileno para reconocer la jurisdicción de la Corte. Esta nueva disposición calificó su competencia de subsidiaria, según lo señalado en el tratado que instituye dicha Corte. Gracias a esta disposición, una sentencia del Tribunal Constitucional del mismo año declaró que el Estatuto de Roma no contiene normas que se opongan a la Constitución Política de la República de Chile. Pero ¿̇en qué momento pasó la jurisdicción de la Corte Penal Internacional, de correctiva y sustitutiva a complementaria y subsidiaria? El presente artículo busca responder esta pregunta.

PALABRAS CLAVE: Tribunal Constitucional - Estatuto de Roma Corte Penal Internacional - Jurisdicción - Complementariedad

\section{THE COMPLEMENTARITY OF THE INTERNATIONAL CRIMINAL COURT ACCORDING TO THE CHILEAN CONSTITUTIONAL TRIBUNAL}

ABSTRACT: A decision of the Constitutional Tribunal declared in 2002 that the approval and subsequent ratification of the Rome Statute

* Trabajo presentado en Antofagasta el 25 de agosto de 2011, en el III Coloquio de Jurisprudencia Constitucional organizado por la Escuela de Derecho de la Universidad Católica del Norte.

Fecha recepción: 9 de septiembre de 2011.

Fecha de aceptación: 12 de enero de 2012.

** PhD (U. of Edinburgh), LLM (U. de Leiden), Abogado y Licenciado en Derecho (U. Católica de Chile). Profesor de Derecho Internacional e investigador de la Facultad de Derecho de la Pontificia Universidad Católica de Chile. Correo electrónico: sebastianlopeze@googlemail.com 
would require a previous constitutional reform. Among the reasons mentioned, the decision emphasized the supposed corrective and substitutive character of the jurisdiction of the International Criminal Court, with respect to the competence of national tribunals. The introduction of a new transitory provision to our political constitution in 2009 authorised the Chilean state to recognise the jurisdiction of the court. This new provision described its competence as subsidiary, according to the treaty that established this court. Thanks to this provision, a decision of the Constitutional Tribunal of the same year declared that the Rome Statute does not include norms that contradict the Political Constitution of the Republic of Chile. But, at which moment did the jurisdiction of the International Criminal Court was transformed from corrective and substitutive, to complementary and subsidiary? The present article aims to answer this question.

KEY WORDS: Constitutional Tribunal - Rome Statue - International Criminal Court Jurisdiction - Complementarity

\section{INTRODUCCIÓN}

El 24 de junio de 2009, el Tribunal Constitucional de Chile (en adelante, TC) declaró que el Estatuto de Roma de 1998, por el cual se establece la Corte Penal Internacional (en adelante, CPI), no contiene normas contrarias a nuestra carta fundamental. Con esta breve sentencia, se puso término a un período de más de siete años de incertidumbre respecto a la participación de Chile en dicho tratado, que comenzó con otra sentencia del TC: la del 8 de abril de 2002, que declaró que el Estatuto de Roma requería de una reforma constitucional previa a su aprobación por el Congreso Nacional y su ratificación por el Presidente de la República. ¿Qué ocurrió entre ambas resoluciones, que transformó en constitucional al tratado que instituye la CPI? Al parecer, no mucho más que la introducción de una disposición transitoria a la Constitución Política de la República de Chile (CPR) que dice lo siguiente:

"El Estado de Chile podrá reconocer la jurisdicción de la Corte Penal Internacional en los términos previstos en el tratado aprobado en la ciudad de Roma, el 17 de julio de 1998, por la Conferencia Diplomática de Plenipotenciarios de las Naciones Unidas sobre el establecimiento de dicha Corte.

Al efectuar ese reconocimiento, Chile reafirma su facultad preferente para ejercer su jurisdicción penal en relación con la jurisdicción de la Corte. Esta última será subsidiaria de la primera, en los términos previstos en el Estatuto de Roma que creó la Corte Penal Internacional. 
La cooperación y asistencia entre las autoridades nacionales competentes y la Corte Penal Internacional, asi como los procedimientos judiciales y administrativos a que hubiere lugar, se sujetarán a lo que disponga la ley chilena.

La jurisdicción de la Corte Penal Internacional, en los términos previstos en su Estatuto, solo se podrá ejercer respecto de los crimenes de su competencia cuyo principio de ejecución sea posterior a la entrada en vigor en Chile del Estatuto de Roma ${ }^{1}$.

Sin embargo, en su sentencia rol 346-02 el TC había identificado diversas inconstitucionalidades que afectaban a dicho tratado. Primero, la naturaleza jurídica correctiva y sustitutiva o supletoria de la competencia de la CPI, en relación a las jurisdicciones nacionales ${ }^{2}$. Como señalara el TC en esa oportunidad, de la lectura del Estatuto de Roma "resulta evidente que la Corte puede corregir lo resuelto por los tribunales nacionales de los Estados Parte, pudiendo, en consecuencia, decidir en contra de lo obrado por ellos y, en determinadas situaciones, de ausencia real o formal de dichos tribunales nacionales, sustituirlos"3. El TC concluyó que:

"el Estatuto de la Corte Penal Internacional, al establecer una jurisdicción que puede ser correctiva y sustitutiva de las nacionales, más que complementar a estas, está prorrogando a una jurisdicción nueva, no contemplada en nuestro ordenamiento constitucional, la facultad de abrir procesos penales por delitos cometidos en Chile, lo que importa, por ende, una transferencia de soberanía que, por no estar autorizada en nuestra Carta Política, vulnera en su esencia el artículo $5^{\circ}$, inciso primero, de la Constitución" 4 .

Segundo, el TC consideró a la CPI como un tribunal distinto a la Corte Interamericana de Derechos Humanos y la Corte Internacional de Justicia, en virtud de la supervigilancia correctiva y sustitutiva que tendría de las resoluciones de los tribunales nacionales ${ }^{5}$. Debido a que la CPR entrega el ejercicio de la jurisdicción para conocer conflictos ocurridos dentro del territorio de la República a los tribunales establecidos por ella o por la ley, en forma privativa y excluyente, el TC consideró que el Esta-

\footnotetext{
1 Disposición 24 transitoria de la CPR.

2 Tribunal Constitucional. 8 de abril de 2002. Rol N ${ }^{\circ}$ 346-02. "Requerimiento de inconstitucionalidad presentado por treinta y cinco seńores diputados respecto del Estatuto de Roma de la Corte Penal Internacional, adoptado en dicha ciudad el 17 de julio de 1998 ”.

Disponible en http://www.tribunalconstitucional.cl/wp/descargar_expediente.php?id=29305 [fecha de visita 5 de septiembre de 2011]. Considerando 23.

3 TC Rol N³46-02. Considerando 24.

Ver, también, TC Rol No 346-02. Considerando 25.

4 TC Rol N ${ }^{\circ}$ 346-02. Considerando 31.

$5 \quad$ TC Rol No 346-02. Considerando 33.
} 
tuto de Roma era contrario a los artículos 5, 6, 7, 19 número 3, y 73 de la Carta Fundamental ${ }^{6}$. Tercero, el TC estimó que el Estatuto de Roma no se conformaba con la CPR en lo relativo a los indultos y amnistías, debido a que la CPI podría desconocerlos en sus sentencias, lo que no se ajustaría a los artículos 32 número 16, y 60 número 16 de la carta fundamental ${ }^{7}$. Cuarto, el TC declaró que el Estatuto de Roma vulnera la CPR en sus artículos 58, 78, y 81 inciso 4, ya que de su sola lectura:

"aparece con nitidez que el fuero parlamentario y las prerrogativas penales de los magistrados de los tribunales superiores de justicia, los fiscales judiciales y los jueces que integran el Poder Judicial y de los Ministros del Tribunal Constitucional, el Fiscal Nacional, los fiscales regionales y los fiscales adjuntos quedan sin efecto porque el Estatuto hace desaparecer este sistema, ya que prevé un procesamiento directo ante la Corte, lo que resulta incompatible con las disposiciones constitucionales precedentemente citadas" 8 .

Finalmente, en relación a las funciones del fiscal de la CPI, el TC indicó en su sentencia de 2002 que el Estatuto de Roma otorga determinadas facultades que infringen el artículo $80 \mathrm{~A}$ de la CPR, que encarga en forma exclusiva y excluyente al Ministerio Público la dirección de la investigación de los hechos constitutivos de delito9. Todo lo anteriormente seńalado requería -en opinión del TC- una reforma constitucional previa a su aprobación por el Legislativo y su ratificación por el Ejecutivo ${ }^{10}$.

$6 \quad$ TC Rol No 346-02. Considerandos 44-6.

Según el TC, las materias cuyo conocimiento se entrega a la CPI son improrrogables, puesto que se trata de derechos indisponibles.

TC Rol N 346-02. Considerando 50.

Ver, también, TC Rol No 346-02. Considerandos 52 \& 54-6.

El TC estimó que el Estatuto de Roma vulnera, asimismo, la CPR en sus artículos 73 a 79.

TC Rol N ${ }^{\circ}$ 346-02. Considerandos 57-8.

$7 \quad$ TC Rol No 346-02. Considerandos 78-9.

$8 \quad$ TC Rol N ${ }^{\circ} 346-02$. Considerando 88.

Ver, también, TC Rol N³46-02. Considerandos 83 \& 85-6.

$9 \quad$ TC Rol N³46-02. Considerando 89.

10 Cabe destacar que la sentencia rol 346-02 del TC fue acordada con el voto en contra del ministro Marcos Libedinsky, quien consideró innecesaria una reforma constitucional anterior a dicha aprobación y ratificación. En su opinión, los aparentes obstáculos constitucionales del Estatuto de Roma podían ser salvados a través de la interpretación adecuada de las normas involucradas. 


\section{1) LA SENTENCIA ROL 1415-09 DEL TC}

Siete años después de haber considerado inconstitucional el Estatuto de Roma, el TC volvió a pronunciarse al respecto. Esta vez, en sentido contrario basándose en la reforma introducida a nuestra Carta Fundamental por la Ley $\mathrm{N}^{\circ} 20.352$ de 2009 , que incluyó una nueva disposición 24 transitoria a la CPR ${ }^{11}$. En la sentencia rol 1415-09, el TC se limitó a seńalar que el tratado que instituye la CPI no contiene normas orgánicas contrarias a la CPR. En su voto concurrente, la ministra Marisol Peńa transcribe el informe de la Corte Suprema del 19 de junio de 2009, que afirmó que "con la reforma constitucional antes citada se resguarda suficientemente la jurisdicción nacional en lo que se refiere al carácter subsidiario de las normas del tratado en relación a esta potestad, y atendida la irretroactividad que asegura dicho cuerpo normativo, este puede ser informado positivamente" 12 . Nada más dice la sentencia del TC respecto a la constitucionalidad del Estatuto de Roma.

Revisando la nueva disposición 24 transitoria de la CPR, se puede concluir que el hecho de no estar la CPI entre las autoridades que la CPR y la ley chilena contemplan, se salvaría en su inciso primero cuando dice que "[e]l Estado de Chile podrá reconocer la jurisdicción de la Corte Penal Internacional en los términos previstos en [dicho] tratado". En cuanto a otros problemas identificados por el TC en su sentencia rol 346-02 -indultos y amnistías, fuero parlamentario y prerrogativas penales de jueces y fiscales nacionales, funciones del fiscal de la CPI- el inciso tercero de esta disposición los solucionaría al señalar que: "[l]a cooperación y asistencia entre las autoridades nacionales competentes y la Corte Penal Internacional, así como los procedimientos judiciales y administrativos a que hubiere lugar, se sujetarán a lo que disponga la ley chilena". No obstante, respecto a la supuesta naturaleza jurídica correctiva y sustitutiva o supletoria de la jurisdicción del CPI, la nueva disposición transitoria simplemente dice que con el reconocimiento de la competencia del tribunal internacional, nuestro Estado "reafirma su facultad preferente para ejercer su jurisdicción penal en relación con la jurisdicción de la Corte. Esta últi-

11 Ver Tribunal Constitucional. 24 de junio de 2009. Rol N 1415-09. "Control de constitucionalidad del proyecto aprobatorio del Estatuto de Roma de la Corte Penal Internacional, adoptado en dicha ciudad el 17 de julio de 1998”.

Disponible en http://www.tribunalconstitucional.cl/wp/descargar_expediente.php?id=1948 [fecha de visita 5 de septiembre de 2011]. Considerandos 3-4.

12 En su voto concurrente, la ministra Marisol Peńa identificó las normas del Estatuto de Roma que son propias de ley orgánica constitucional. Estas corresponderían a los artículos $1,4,5,8,11-4,25-6,34-41,44,58-9,70,77-8,80,86-7,89-90,92-5,97-8,101,103-11$ \& 119 , los cuales se refieren a materias indicadas en los dos primeros incisos del artículo 77 de la CPR. Asimismo, identificó a los artículos 14-5, 18-9, 42, 44, 53-4, 86-7, 93-5 \& 97-9 del Estatuto de Roma, los que se refieren a materias del artículo 84 de la CPR. 
ma será subsidiaria de la primera, en los términos previstos en el Estatuto de Roma que creó la Corte Penal Internacional".

El 6 de julio de 2009, el Estado de Chile adhirió al Estatuto de Roma. Atrás quedaron más de diez años de desavenencias entre las entonces fuerzas políticas de gobierno y opositoras. Como parte de la negociación que llevó a la reforma constitucional de ese año, se promulgó la Ley No 20.357 que tipificó los crímenes de lesa humanidad, genocidio y delitos de guerra, contemplando penas de presidio para sus autores y/o responsables. Sorprende que las aparentemente serias inconstitucionalidades identificadas por el TC en el 2002, hayan sido solucionadas a través de una breve disposición ad hoc agregada a la CPR. Revela el carácter casi exclusivamente político que tuvo el proceso de aprobación del Estatuto de Roma en nuestro país, el último inciso de la nueva disposición 24 transitoria, que dice: "La jurisdicción de la Corte Penal Internacional, en los términos previstos en su Estatuto, solo se podrá ejercer respecto de los crímenes de su competencia cuyo principio de ejecución sea posterior a la entrada en vigor en Chile del Estatuto de Roma”. Pareciera que la discusión jurídica sobre el tema en nuestro país se redujo a un asunto concreto y circunstancial: excluir de la competencia de la CPI toda situación producida durante el gobierno militar ${ }^{13}$. Apoya esta conclusión la solución sumaria que se le dio al problema central de la discusión jurídica en torno a la CPI -el carácter complementario de su jurisdicción-14.

13 Desde esta perspectiva, el último inciso de la nueva disposición 24 transitoria de la CPR resultaría innecesario, puesto que el artículo 11 del Estatuto de Roma ya seńala que:

1. La Corte tendrá competencia únicamente respecto de crímenes cometidos después de la entrada en vigor del presente Estatuto.

2. Si un Estado se hace Parte en el presente Estatuto después de su entrada en vigor, la Corte podrá ejercer su competencia únicamente con respecto a los crímenes cometidos después de la entrada en vigor del presente Estatuto respecto de ese Estado, a menos que este haya hecho una declaración de conformidad con el párrafo 3 del artículo 12 [relativa a la aceptación de la jurisdicción de la CPI por un estado que no es parte del Estatuto de Roma, para un crimen determinado].

Sobre las distintas posturas jurídicas relativas a la necesidad de reformar la CPR para aprobar el Estatuto de Roma, ver a favor Fermandois Vöhringer, Arturo (2003). "El Tribunal Penal Internacional y sus implicancias constitucionales". Revista Chilena de Derecho, Vol. 30 No 3, pp. 471-89, y en contra CEA EgAÑA, José Luis (1999). "Mérito constitucional del tratado que establece la Corte Penal Internacional". Ius et Praxis, Vol. 5 No 2, pp. 353-61; Nogueira Alcalá, Humberto (1999). "Consideraciones sobre constitucionalidad del Estatuto de Roma del Tribunal Penal Internacional”. Ius et Praxis, Vol. 5 No 2, pp. 363-87; Troncoso Repetto, Claudio (2000). "La Corte Penal Internacional y el principio de complementariedad". Ius et Praxis, Vol. 6 No 2, pp. 40717; y Nogueira Alcalá, Humberto (2002). "Consideraciones sobre el fallo del Tribunal Constitucional respecto del Tratado de Roma que establece la Corte Penal Internacional”. Ius et Praxis, Vol. 8 No1, pp. 563-81.

Respecto a la postura del gobierno chileno durante el cual se dictó la sentencia rol 34602 del TC, ver Rojas Olivares, Andrea, y Jiménez Salas, Guillermo (editores) (2006): Doctrina constitucional del Presidente Ricardo Lagos Escobar (2000-2006). Santiago: LOM, Vol. 1, 424 pp., en pp. 11-87. 


\section{2) NATURALEZa JURÍDiCA DE LA CPI}

El Derecho Penal Internacional es una rama relativamente reciente que recoge sus normas y principios del Derecho Internacional de los derechos humanos y del Derecho Internacional Humanitario, así como del Derecho Penal Comparado ${ }^{15}$. Su objeto es proscribir crímenes internacionales, e imponer sobre los Estados la obligación de perseguir y sancionar estos crímenes ${ }^{16}$. Por siete años, Chile pasó a engrosar la lista de los países que se marginaron del tratado con que se dio término a la etapa fundacional de esta nueva rama del Derecho Internacional, que empezara en 1945 y 1946 con el establecimiento del Tribunal Militar Internacional de Nuremberg y del Tribunal Militar Internacional para el Lejano Oriente de Tokio ${ }^{17}$. El anhelo de instaurar un tribunal penal internacional de carácter permanente proviene de inicios del período de postguerra -así lo confirma la Convención para la Prevención y Sanción del Delito de Genocidio de 1948-. Durante la década de 1950, la Comisión de Derecho Internacional (CDI) y diferentes comités especiales de la Asamblea General de la ONU trabajaron en el tema, preparando diversos informes de proyectos que no llegaron a puerto. En 1989, la CDI retomó la idea de un tribunal penal internacional permanente, el cual vio finalmente la luz nueve ańos después en una conferencia en Roma. Influyó en su establecimiento la creación por el Consejo de Seguridad de la ONU de dos tribunales penales internacionales ad hoc: uno para la ex Yugoslavia en 1993 y otro para Ruanda en $1994^{18}$. El tratado que instituye la CPI entró

15 Hablamos de rama del derecho internacional, cuando un grupo de normas y principios se extiende y se densifica a tal punto, que requiere un estudio especial y separado.

Dolzer, Rudolph, y Schreuer, Christoph (2008). Principles of International Investment Law. Nueva York, EE.UU.: Oxford University Press, 432 pp., en p. 2.

16 Para estos efectos, se entiende por crimen internacional toda violación a una norma internacional que conlleva la responsabilidad penal personal del individuo respectivo. Esta responsabilidad se refiere no solo a quien cometió el delito como autor, sino también a quienes facilitaron la comisión de su acto.

Ver Cassese, Antonio (2006): “International Criminal Law”. En Evans, Malcolm (editor): International Law. Nueva York, EE.UU.: Oxford University Press, pp. 719-52, en pp. 71923.

Sobre los crímenes internacionales, ver en general CASSESE, Antonio (2008). International Criminal Law. Nueva York, EE.UU.: Oxford University Press, 455 pp., en pp. 81-183.

17 Sobre los tribunales de Nuremberg y Tokio, ver Overy, Richard (2006): “The Nuremberg Trials: International Law in the Making”. En sAnds, Philippe (editor): From Nuremberg to The Hague: The Future of International Criminal Justice. Cambridge, Reino Unido: Cambridge University Press, pp. 1-29; Bantekas, Ilias, y Nash, Susan (2007). International Criminal Law. Nueva York, EE.UU.: Routledge-Cavendish, 594 pp., en pp. 495-508; y Röling, Bert, y Cassese, Antonio (1994). The Tokyo Trial and Beyond: Reflections of a Peacemonger. Cambridge, EE.UU.: Polity Press, 143 pp.

18 Sobre los numerosos problemas que debió sortear el establecimiento de la CPI, ver Crawford, James (2006): “The Drafting of the Rome Statute". En sands, Philippe 
en vigencia el 2002, y tiene actualmente un buen número de partes -más de cien estados ${ }^{19}$

Según el preámbulo y el artículo 5 (1) del Estatuto de Roma, la jurisdicción de la CPI cubre "los crímenes más graves de trascendencia para la comunidad internacional en su conjunto" ${ }^{20}$. Conforme al mismo artículo 5 (1), estos son el genocidio, los crímenes contra la humanidad, los crímenes de guerra, y el crimen de agresión. Todos son imprescriptibles ${ }^{21}$. Siendo un tribunal internacional permanente e independiente, con personalidad jurídica propia ${ }^{22}$, el Derecho aplicable en los procedimientos ante este será: primero, el Estatuto de Roma y sus reglamentos; segundo, y

(editor): From Nuremberg to The Hague: The Future of International Criminal Justice. Cambridge, Reino Unido: Cambridge University Press, pp. 109-56.

Ver, también, Philipp, Christiane (2003). "The International Criminal Court - A Brief Introduction". Max Planck Yearbook of United Nations Law, Vol. 7, pp. 331-9; Bantekas y NASH (2007) 509-11; y CASSESE (2008) 317-30.

En castellano, ver OTtenhoff, Reynald (2006). "La justicia penal internacional en el tercer milenio: surgimiento de la Corte Penal Internacional”. Eguzkilore - Cuaderno del Instituto Vasco de Criminología, No. 20, pp. 75-82; y Lirola Delgado, Isabel, y Martín Martínez, Magdalena (2001). La Corte Penal Internacional: justicia versus impunidad. Barcelona, Espańa: Editorial Ariel, 307 pp., en pp. 37-60.

19 Información disponible en http://treaties.un.org/pages/ViewDetails.aspx?src=IND\&mtdsg_ no=XVIII-10\&chapter $=18 \&$ lang=en [fecha de visita 5 de septiembre de 2011].

Las ausencias de China, Egipto, EE.UU., India, Irán, Israel y Pakistán resultan particularmente evidentes en un tribunal que tiene vocación de universal.

Sobre EE.UU. y el Estatuto de Roma, ver Brown, Bartram (1999). "U.S. Objections to the Statute of the International Criminal Court: A Brief Response". New York University Journal of International Law and Politics, Vol. 31, pp. 855-91; Zwanenburg, Marten (1999). "The Statute for an International Criminal Court and the United States: Peacekeepers under Fire?". European Journal of International Law, Vol. 10 No1, pp. 124-43; SANDs, Philippe (2005). Lawless World: America and the Making and Breaking of Global Rules. Londres, Reino Unido: Allen Lane / Penguin, 324 pp., en pp. 46-68; VAN DER Wilt, Harmen (2005). "Bilateral Agreements between the United States and State Parties to the Rome Statute: Are They Compatible with the Object and Purpose of the Statute?" Leiden Journal of International Law, Vol. 10 No1, pp. 93-111. Párrafo cuarto.

Ver, también, artículo 1 del Estatuto de Roma.

Sobre el tratado que instituye la CPI en general, ver Arsanjani, Mahnoush (1999). "The Rome Statute of the International Criminal Court". American Journal of International Law, Vol. 93 No1, pp. 22-43; Cassese, Antonio (1999). "The Statute of the International Criminal Court: Some Preliminary Reflections". European Journal of International Law, Vol. 10 No1, pp. 144-71; Sarooshi, Danesh (1999). "The Statute of the International Criminal Court”. International \& Comparative Law Quarterly, Vol. 48 No2, pp. 387-404; y BANTEKAS y NASH (2007) 535-55.

21 Artículo 29 del Estatuto de Roma.

Se define al genocidio en el artículo 6, a los crímenes de lesa humanidad en el artículo 7, y a los crímenes de guerra en el artículo 8.

En relación al crimen de agresión, el artículo 5 (2) indica que la CPI ejercerá competencia respecto de este "una vez que se apruebe una disposición [...] en que se defina el crimen". Hasta la fecha, tal definición no ha sido adoptada. tratado. 
cuando proceda, los tratados, normas y principios de Derecho Internacional; y tercero, los Principios Generales del Derecho que derive la CPI de las diferentes Derechos nacionales, siempre que no sean contrarios al Estatuto o a las normas y principios de Derecho Internacional ${ }^{23}$. Es en este contexto que se inserta el principio rector de la jurisdicción de la CPI.

\section{3) EL PRINCIPIO DE LA COMPLEMENTARIEDAD}

¿Qué se entiende por competencia complementaria? En su sentencia rol 346-02, el TC concluyó que la jurisdicción de la CPI era correctiva e incluso sustitutiva de las jurisdicciones nacionales ${ }^{24}$. Según el TC, el Estatuto de Roma no conferiría preferencia a los Estados que estén en condiciones de ejercer su jurisdicción penal interna, en virtud de los principios de nacionalidad o de territorialidad, para la sanción de los crímenes descritos en dicho tratado ${ }^{25}$. Por el contrario, al establecer una jurisdicción correctiva y sustitutiva de las competencias nacionales, el Estatuto de Roma estaría prorrogando una jurisdicción nueva no contemplada en nuestro ordenamiento jurídico, lo que importaría una transferencia de soberanía no autorizada por la $\mathrm{CPR}^{26}$. Esta conclusión se deriva de la siguiente constatación, que hiciera el mismo tribunal: el Estatuto de Roma no define el significado del carácter complementario de la jurisdicción de la $\mathrm{CPI}^{27}$. La disposición 24 transitoria de la CPR -introducida en el 2009- tampoco lo hizo, ya que solo reafirmó la facultad preferente del Estado de Chile para ejercer su jurisdicción penal, agregando que la competencia de la CPI será subsidiaria de la primera "en los términos previstos en el Estatuto de Roma". Esto nos obliga a recurrir a dicho tratado, así como a la doctrina internacionalista, para determinar qué se entiende por complementariedad ${ }^{28}$.

El preámbulo del tratado que instituye la CPI reconoce que "es deber de todo Estado ejercer su jurisdicción penal contra los responsables de crímenes" 29 . A la vez destaca que "nada de lo dispuesto en el presente Estatuto deberá entenderse en el sentido de que autorice a un Estado Parte a intervenir [...] en los asuntos internos de otro Estado" 30 . Asimismo, agrega el preámbulo que la CPI "establecida en virtud del presente Esta-

Artículo 21 del Estatuto de Roma.

TC Rol No 346-02. Considerandos 22-4.

TC Rol No 346-02. Considerando 22.

TC Rol No 346-02. Considerando 31.

TC Rol No 346-02. Considerando 21.

No hay jurisprudencia relevante de la CPI al respecto.

Párrafo sexto.

Párrafo octavo. 
tuto será complementaria de las jurisdicciones penales nacionales" 31 . Esto es corroborado, en términos similares, por el artículo primero del tratado. Más adelante, el artículo 17 del Estatuto de Roma seńala detalladamente que:

1. La Corte teniendo en cuenta el décimo párrafo del preámbulo y el artículo 1 [ya mencionados], resolverá la inadmisibilidad de un asunto cuando:

a) El asunto sea objeto de una investigación o enjuiciamiento en el Estado que tiene jurisdicción sobre él salvo que este no esté dispuesto a llevar a cabo la investigación o el enjuiciamiento o no pueda realmente hacerlo;

b) El asunto haya sido objeto de investigación por el Estado que tenga jurisdicción sobre él y este haya decidido no incoar acción penal contra la persona de que se trate, salvo que la decisión haya obedecido a que no esté dispuesto a llevar a cabo el enjuiciamiento o no pueda realmente hacerlo;

c) La persona de que se trate haya sido ya enjuiciada por la conducta a que se refiere la denuncia, y la Corte no pueda incoar el juicio con arreglo a lo dispuesto en el párrafo 3 del artículo $20^{32}$;

d) El asunto no sea de gravedad suficiente para justificar la adopción de otras medidas por la Corte.

2. A fin de determinar si hay o no disposición a actuar en un asunto determinado, la Corte examinará, teniendo en cuenta los principios de un proceso con las debidas garantías reconocidos por el derecho internacional, si se da una o varias de las siguientes circunstancias, según el caso:

a) Que el juicio ya haya estado o esté en marcha o que la decisión nacional haya sido adoptada con el propósito de sustraer a la persona de que se trate de su responsabilidad penal por crímenes de la competencia de la Corte, según lo dispuesto en el artículo 5 [sobre crímenes de competencia de la CPI];

Párrafo décimo.

Este párrafo tercero del artículo 20 dice:

La Corte no procesará a nadie que haya sido procesado por otro tribunal en razón de hechos también prohibidos en virtud de los artículos 6, 7 u 8 [relativos al genocidio, los crímenes de lesa humanidad, y los crímenes de guerra, respectivamente] a menos que el proceso en el otro tribunal: a) Obedeciera al propósito de sustraer al acusado de su responsabilidad penal por crímenes de la competencia de la Corte; o

b) No hubiere sido instruida en forma independiente o imparcial de conformidad con las debidas garantías procesales reconocidas por el derecho internacional o lo hubiere sido de alguna manera que, en las circunstancias del caso, fuere incompatible con la intención de someter a la persona a la acción de la justicia. 
b) Que haya habido una demora injustificada en el juicio que, dadas las circunstancias, sea incompatible con la intención de hacer comparecer a la persona de que se trate ante la justicia;

c) Que el proceso no haya sido o no esté siendo sustanciado de manera independiente o imparcial y haya sido o esté siendo sustanciado de forma en que, dadas las circunstancias, sea incompatible con la intención de hacer comparecer a la persona de que se trate ante la justicia.

3. A fin de determinar la incapacidad para investigar o enjuiciar en un asunto determinado, la Corte examinará si el Estado, debido al colapso total o sustancial de su administración nacional de justicia o al hecho de que carece de ella, no puede hacer comparecer al acusado, no dispone de las pruebas y los testimonios necesarios o no está por otras razones en condiciones de llevar a cabo el juicio ${ }^{33}$.

De la lectura de las normas precedentes, se desprende que la jurisdicción de la CPI no busca reemplazar la competencia de los tribunales nacionales. Son ellos los primeros llamados a conocer los crímenes cometidos dentro de su territorio, por sus nacionales o que los afecten. Con la complementariedad se respetaría - por tanto- la soberanía estatal, con una salvedad -que el Estado respectivo no quiera o no pueda investigar o procesar al individuo correspondiente ${ }^{34}-$.

\section{4) COMPETENCIA ¿SUBSIDIARIA?}

Que la jurisdicción de la CPI sea complementaria significa que esta no puede conocer un crimen, respecto del cual esté ejerciendo debidamente su competencia un tribunal nacional. Puede ocurrir, por ejemplo, que las autoridades locales estén investigando o procesando a un individuo determinado, de manera adecuada. En ese caso, la CPI no podría ejercer su jurisdicción. Tampoco lo podría hacer si las autoridades locales deciden no procesar a un individuo, o deciden condenarlo o declararlo inocente, también de manera adecuada: vale decir, a través de un debido proceso. ¿Cuándo podría, entonces, ejercer su jurisdicción la CPI? Solo en aquellos casos en que el Estado no quiera o no pueda investigar o pro-

33 Se relacionan también con el principio de complementariedad, los artículos 15, 18 (1) y 19, relativos a las funciones del fiscal de la CPI y a la impugnación de su competencia.

$34 \mathrm{Al}$ establecer la complementariedad de la jurisdicción de la CPI se tuvo también en cuenta una razón de carácter práctico: sin ella, la CPI se vería inundada de casos provenientes de todo el mundo. Teniendo recursos limitados, la CPI no sería capaz de responder a una situación de esa naturaleza.

Ver Cassese (2008) 343. 
cesar. Aquí la competencia de la CPI primaría sobre la jurisdicción de los tribunales nacionales, aun cuando el caso respectivo esté pendiente ante las autoridades locales ${ }^{35}$. El mismo Estatuto de Roma se encarga de aclarar, en los párrafos segundo y tercero de su artículo 17, qué debe entenderse por no querer o no poder investigar o procesar a alguien. La falta de disposición para actuar consiste en que las autoridades nacionales hayan adoptado medidas destinadas a evitar que se establezca la responsabilidad penal del individuo correspondiente; en que haya una demora injustificada en el proceso, que ponga en evidencia el desinterés de las autoridades por traer a esa persona ante la justicia; y en que el proceso no sea sustanciado de manera independiente o imparcial, evidenciando el desinterés ya mencionado. La falta de capacidad para actuar, en tanto, se refiere a un colapso tal del sistema judicial respectivo, que impida llevar a cabo el juicio correspondiente ${ }^{36}$.

La complementariedad se aplica cualquiera sea la forma en que se active la jurisdicción de la CPI: bien que la situación haya sido referida al fiscal por un Estado parte del Estatuto de Roma ${ }^{37}$; que haya sido iniciada de oficio por el fiscal, con la autorización de la sala de cuestiones preliminares ${ }^{38}$; o que haya sido referida al fiscal por el Consejo de Seguridad de la ONU, actuando bajo el Capítulo VII de su Carta ${ }^{39}$. Como señala Antonio Cassese, el problema de la complementariedad se plantea en aquellos casos de competencia concurrente de uno o más Estados y la CPI, respecto de los crímenes señalados en el artículo 5 del Estatuto de Roma: i.e. genocidio, crímenes contra la humanidad, crímenes de guerra, y crimen de agresión. Al no haber normas de Derecho Internacional General que resuelvan el asunto, se debe buscar la solución en el tratado constituyente respectivo ${ }^{40}$. Los estatutos de los tribunales penales internacionales para la ex Yugoslavia y para Ruanda, establecían la primacía de la jurisdicción internacional por sobre las nacionales, en caso de competencias concurrentes $^{41}$. No se optó por esta solución en el Estatuto de Roma, sino

\footnotetext{
35 CASSESE (2008) 343.

CASSESE (1999) 158-9.

36 Zimmermann, Andreas (1998) “The Creation of a Permanent Criminal Court”. Max Planck Yearbook of United Nations Law, Vol. 2, pp. 169-237, en pp. 220-2.

37 Artículos 13 (a) y 14 del Estatuto de Roma.

38 Artículos 13 (c) y 15.

39 Artículos 13 (b) y 52 (c).

40 CASSESE (2008) 336-9.

41 Artículo 9 del Estatuto del Tribunal Penal Internacional para la ex Yugoslavia de 1993, y artículo 8 del Estatuto del Tribunal Penal Internacional para Ruanda de 1994.

La primacía de estos tribunales internacionales ad hoc se estableció teniendo en cuenta la falta de voluntad o de capacidad de las jurisdicciones internas de la ex Yugoslavia o de Ruanda para llevar adelante debidos procesos con posterioridad a los conflictos que asolaron a estos países.

Cassese (2008) 339.
} 
que por el principio contrario: la prioridad de la jurisdicción nacional por sobre la de la CPI ${ }^{42}$. Como el mismo Cassese indica, subsidiariedad es sinónimo de complementariedad ${ }^{43}$. Concuerda con esto James Crawford, quien participó en una de las etapas del proceso de redacción del Estatuto de Roma. Según Crawford se evitó calificar de subsidiaria a la jurisdicción de la CPI, por cuanto dicho término ya había sido utilizado por el Tratado de Maastricht de 1992 para referirse a la relación entre el Derecho de la Unión Europea y los Derechos Nacionales correspondientes ${ }^{44}$. Complementaria o subsidiaria, el principio rector de la competencia de la CPI seguiría siendo el mismo: su rol es secundario, respecto de los tribunales internos ${ }^{45}$.

\section{CONCLUSIÓN}

En su análisis del Estatuto de Roma en el 2002, el TC detectó importantes inconstitucionalidades que exigían una reforma de la Carta Fundamental por el Legislativo, como requisito necesario para la posterior adhesión a dicho tratado por el ejecutivo. Dada la importancia de los problemas detectados entonces por el TC, bien se podría haber esperado una modificación de cierta relevancia a la CPR. La reforma de 2009, en cambio, introdujo una disposición transitoria que -en esencia- otorga una simple autorización ad hoc al Estado chileno para adherir el Estatuto de Roma. En virtud de esta breve modificación de la CPR, el TC declaró constitucional al tratado instituyente de la CPI, sin entrar en detalles respecto de lo fallado por el mismo tribunal siete ańos antes. Leer la sentencia rol 1415-09 es decepcionante. Las expectativas creadas por lo que

A pesar de lo anterior, los tribunales penales internacionales para la ex Yugoslavia y Ruanda reconocieron que, en ciertos casos, podría prevalecer la competencia de los tribunales nacionales. Al respecto ver CASSESE (2008) 339-42.

42 Ver Zimmermann (1998), pp. 219-20; Zwanenburg (1999), pp. 130-2; y Wagner, Markus (2003). "The ICC and its Jurisdiction - Myths, Misperceptions and Realities". Max Planck Yearbook of United Nations Law, Vol. 7, pp. 409-512, en pp. 505-6.

43 CASSESE (2008), 342.

44 CRAWFORD (2006) 109-11 \& 138-9.

45 CrawFord (2006) 138-9.

Para un estudio más detallado de la complementariedad de la CPI, ver en general BENZING, Markus (2003). "The Complementarity Regime of the International Criminal Court: International Criminal Justice between State Sovereignty and the Fight Against Impunity". Max Planck Yearbook of United Nations Law, Vol. 7, pp. 591-632.

Sobre la recepción del Estatuto de Roma en Latinoamérica, ver Malarino, Ezequiel (2006): "Evaluación comparativa. Implementación y dificultades de implementación del Estatuto de Roma a la luz de la experiencia latinoamericana”. En Aмвos, Kai, Malarino, Ezequiel, y Woischnik, Jan (editores): Dificultades juridicas y politicas para la ratificación o implementación del Estatuto de Roma de la Corte Penal Internacional. Montevideo, Uruguay: Konrad Adenauer Stiftung, pp. 489-512. 
parecía un debate jurídico de cierto vuelo, quedan defraudadas por esta resolución que solo viene a corroborar un arreglo político entre las fuerzas de la Alianza por Chile y la Concertación de Partidos por la Democracia, mediante el cual se excluye de la jurisdicción de la CPI cualquier asunto relacionado con el último gobierno militar. Queda particularmente de manifiesto lo anterior, cuando se estudia la solución dada al problema de la complementariedad de la CPI. En su sentencia de 2002, el TC calificó a la jurisdicción de la CPI como correctiva y sustitutiva de la competencia de los tribunales nacionales. La nueva disposición 24 transitoria de la CPR simplemente reafirmó la facultad preferente del Estado de Chile para ejercer su jurisdicción, agregando que la competencia de la CPI será subsidiaria de esta, según lo seńalado en el mismo Estatuto de Roma. Sin embargo, el tratado que instituye la CPI decía lo mismo tanto en el 2009 como en el 2002. Conforme al estatuto, y la doctrina internacionalista que lo explica, la jurisdicción de la CPI tiene un rol secundario a la competencia de los tribunales nacionales. En otras palabras, aun cuando nada agregó la reforma del 2009 a este respecto, el TC pasó de considerar la jurisdicción de la CPI como correctiva y sustitutiva, a complementaria y subsidiaria.

Lo que podría haber sido una buena oportunidad para actualizar la CPR, precaviendo nuevas situaciones como la que se produjo en relación al Estatuto de Roma, se perdió al optar por una solución ad hoc de dudosa técnica jurídica. La relación entre el Derecho Internacional y el Derecho chileno sigue sin estar debidamente regulada en nuestra Carta Fundamental. En consecuencia, continuamos a merced de las oscilaciones de la doctrina y la jurisprudencia nacionales al respecto. Esto produce que cada vez que se presente un problema relativo a la constitucionalidad de un tratado, quede en las manos de las fuerzas políticas del momento alcanzar un arreglo sobre la base de criterios de conveniencia maquillados de jurídicos, lo que va en desmedro del desarrollo del Derecho Público chileno.

\section{BiBLIOGRAFÍA}

- Arsanjani, Mahnoush (1999). "The Rome Statute of the International Criminal Court". American Journal of International Law, Vol. 93 No1, pp. 22-43.

- Bantekas, Ilias, y NASH, Susan (2007). International Criminal Law. Nueva York, EE.UU.: Routledge-Cavendish, 594 pp.

- Benzing, Markus (2003). "The Complementarity Regime of the International Criminal Court: International Criminal Justice between State Sovereignty and the Fight Against Impunity". Max Planck Yearbook of United Nations Law, Vol. 7, pp. 591-632. 
- Brown, Bartram (1999). "U.S. Objections to the Statute of the International Criminal Court: A Brief Response". New York University Journal of International Law and Politics, Vol. 31, pp. 85591.

- Cassese, Antonio (2008). International Criminal Law. Nueva York, EE.UU.: Oxford University Press, 455 pp.

- Cassese, Antonio (2006). "International Criminal Law". En Evans, Malcolm (editor): International Law. Nueva York, EE.UU.: Oxford University Press, pp. 719-52.

- Cassese, Antonio (1999). "The Statute of the International Criminal Court: Some Preliminary Reflections". European Journal of International Law, Vol. 10 No1, pp. 144-71.

- Cea Egaña, José Luis (1999). "Mérito constitucional del tratado que establece la Corte Penal Internacional”. Ius et Praxis, Vol. 5 No 2, pp. 353-61.

- Crawford, James (2006). "The Drafting of the Rome Statute". En sands, Philippe (editor): From Nuremberg to The Hague: The Future of International Criminal Justice. Cambridge, Reino Unido: Cambridge University Press, pp. 109-56.

- Dolzer, Rudolph, y Schreuer, Christoph (2008). Principles of International Investment Law. Nueva York, EE.UU.: Oxford University Press, $432 \mathrm{pp}$.

- Fermandois Vöhringer, Arturo (2003). "El Tribunal Penal Internacional y sus implicancias constitucionales". Revista Chilena de Derecho, Vol. 30 No 3, pp. 471-89.

- Lirola Delgado, Isabel, y Martín Martínez, Magdalena (2001). La Corte Penal Internacional: justicia versus impunidad. Barcelona, Espańa: Editorial Ariel, 307 pp.

- Malarino, Ezequiel (2006). "Evaluación comparativa. Implementación y dificultades de implementación del Estatuto de Roma a la luz de la experiencia latinoamericana”. En Амвоs, Kai, Malarino, Ezequiel, y Woischnik, Jan (editores): Dificultades jurídicas y politicas para la ratificación o implementación del Estatuto de Roma de la Corte Penal Internacional. Montevideo, Uruguay: Konrad Adenauer Stiftung, pp. 489-512.

- Nogueira Alcalá, Humberto (1999). "Consideraciones sobre constitucionalidad del Estatuto de Roma del Tribunal Penal Internacional". Ius et Praxis, Vol. 5 No 2, pp. 363-87.

- Nogueira Alcalá, Humberto (2002). "Consideraciones sobre el fallo del Tribunal Constitucional respecto del Tratado de Roma que establece la Corte Penal Internacional". Ius et Praxis, Vol. 8 No1, pp. 563-81. 
- Otenhoff, Reynald (2006). "La justicia penal internacional en el tercer milenio: surgimiento de la Corte Penal Internacional". Eguzkilore - Cuaderno del Instituto Vasco de Criminología, No. 20, pp. 75-82.

- Overy, Richard (2006). "The Nuremberg Trials: International Law in the Making". En SANDS, Philippe (editor): From Nuremberg to The Hague: The Future of International Criminal Justice. Cambridge, Reino Unido: Cambridge University Press, pp. 1-29.

- Philipp, Christiane (2003). "The International Criminal Court - A Brief Introduction". Max Planck Yearbook of United Nations Law, Vol. 7, pp. 331-9.

- Rojas Olivares, Andrea, y Jiménez salas, Guillermo (editores) (2006). Doctrina constitucional del Presidente Ricardo Lagos Escobar (2000-2006). Santiago: LOM, Vol. 1, 424 pp.

- Röling, Bert, y Cassese, Antonio (1994). The Tokyo Trial and Beyond: Reflections of a Peacemonger. Cambridge, EE.UU.: Polity Press, 143 pp.

- Sands, Philippe (2005). Lawless World: America and the Making and Breaking of Global Rules. Londres, Reino Unido: Allen Lane I Penguin, $324 \mathrm{pp}$.

- SArooshi, Danesh (1999). "The Statute of the International Criminal Court". International \& Comparative Law Quarterly, Vol. 48 No2, pp. 387-404.

- Troncoso Repetto, Claudio (2000). "La Corte Penal Internacional y el principio de complementariedad". Ius et Praxis, Vol. 6 No2, pp. 407-17.

- VAN Der WiLt, Harmen (2005). "Bilateral Agreements between the United States and State Parties to the Rome Statute: Are They Compatible with the Object and Purpose of the Statute?" Leiden Journal of International Law, Vol. 10 No1, pp. 93-111.

- Wagner, Markus (2003). "The ICC and its Jurisdiction - Myths, Misperceptions and Realities". Max Planck Yearbook of United Nations Law, Vol. 7, pp. 409-512.

- Zimmermann, Andreas (1998). "The Creation of a Permanent Criminal Court". Max Planck Yearbook of United Nations Law, Vol. 2, pp. 169-237.

- Zwanenburg, Marten (1999). "The Statute for an International Criminal Court and the United States: Peacekeepers under Fire?” European Journal of International Law, Vol. 10 No1, pp. 124-43. 